\title{
К ВОПРОСУ О ЦИФРОВЫХ ТЕХНОЛОГИЯХ В ПРЕПОДАВАНИИ ИНОСТРАННЫХ ЯЗЫКОВ
}

\section{Ю.С. Максимова \\ Л.C. Торопова \\ Е.К. Караванова}

Статья рассматривает основные тенденции в области развития образования в последние десятилетия, представляя анализ научных и публицистических работ зарубежных и отечественных исследователей в области моделирования образовательного процесса на современном этапе. Авторы данной работы, в частности, обращаются к процессу цифровизации обучения, основным направлениям развития образования в современную эпоху, возможным методикам, приёмам и ресурсам, способствующим переходу с традиционного обучения к смешанному. Смещение фокуса с непосредственного взаимодействия преподавателя и обучаемого в физическом пространстве учебного заведения на виртуальное ставит перед участниками образовательного процесса новые задачи, которые, в частности, могут быть связаны с глобальным развитием искусственного интеллекта в технических сферах. Авторы статьи также обращают внимание на те трудности, которые возникают при обучении иностранным языкам, и предлагают обзор возможных решений.

Ключевые слова: цифровизация, цифровые технологии, образовательные технологии, иностранные языки, смешанное обучение.

\section{ON DIGITAL TECHNOLOGY IN TEACHING FOREIGN LANGUAGE}

Yu.S. Maximova

L.S. Toropova

\section{E.K. Karavanova}

The article examines major tendencies in the education sphere throughout recent decades, analyzing research papers and journalistic writing of national and foreign authors regarding modeling of the current teaching process. The authors of this paper address, in particular, the process of digitalization of education, the main guidance for education development in the modern era, possible methodology, techniques and resources that contribute to the transition from traditional to blended learning. Shifting the focus from the direct teacher-student interaction in the environment of the educational institution to the virtual one places the participants of the process before new challenges, which can relate, in particular, the worldwide development of artificial intelligence in the technology domain. The authors of the article also draw attention to the difficulties that stem from the specificity of teaching foreign languages and suggest a range of possible solutions to the issue at hand.

Keywords: digitalization, digital technologies, methodology, foreign languages, blended learning.

Второе десятилетие нового века предложило беспрецедентное многообразие технологий - как по масштабу, так и по категориям, что оказывает своё воздействие, среди прочего, на сферу образования, ставя перед участниками процесса новые задачи.
Развитие технологий нового времени не могло не отразиться и на образовании, побуждая педагогов к поиску эффективного сочетания традиционных и инновационных форм обучения. Потребность в такого рода соединении уже известного и

Максимова Юлия Сергеевна - кандидат филологических наук, доцент кафедры иностранных языков и межкультурной коммуникации Дальневосточного государственного университета путей сообщения (г. Хабаровск).

Maximova Yulia Sergeevna - Candidate of Philology, Associate Professor of the Department of Foreign Languages and CrossCultural Communication at Far Eastern State Transport University (Khabarovsk).

E-mail: juliamaxprof@gmail.com

Торопова Людмила Сергеевна - кандидат филологических наук, доцент кафедры иностранных языков и межкультурной коммуникации Дальневосточного государственного университета путей сообщения (г. Хабаровск).

Toropova Lyudmila Sergeevna - Candidate of Philology, Associate Professor of the Department of Foreign Languages and Cross-Cultural Communication at Far Eastern State Transport University (Khabarovsk).

E-mail: lyuda_b2004@mail.ru

Караванова Екатерина Константиновна - кандидат филологических наук, доцент кафедры иностранных языков и межкультурной коммуникации Дальневосточного государственного университета путей сообщения (г. Хабаровск).

Karavanova Ekaterina Konstantinovna - Candidate of Philology, Associate Professor of the Department of Foreign Languages and Cross-Cultural Communication at Far Eastern State Transport University (Khabarovsk).

E-mail: karavanova2003@mail.ru 
прокладывающего себе дорогу отмечают как отечественные, так и зарубежные исследователи в области образования, подчёркивая насущную необходимость продуктивного смешанного обучения (см., напр., [4; 10; 13; 19;22; 24;26]).

При необходимости такого подхода к обучению педагоги и методисты стоят перед непростым выбором - каким образом наиболее безболезненно и эффективно перейти к новой модели преподавания и научения. Задача, с одной стороны, чрезвычайно осложняется тотальной цифровизацией практически всех без исключения сфер человеческого бытия, сверхбыстрой сменяемостью событий и нестабильностью окружающей действительности, как отмечает отечественный исследователь профессор Т.В. Черниговская [20].

С другой стороны, современные учащиеся принадлежат к тому поколению, которое уже было рождено в цифровую эпоху, поэтому перед ними не стоит вызов обучиться использованию современных технологий. Напротив, такая задача поставлена временем перед педагогами. Поэтому, по мнению профессора T.В. Черниговской, так востребовано в настоящее время конвергентное образование, которое поможет, с одной стороны, научить детей жить в цифровом мире, разовьет навыки адаптации к постоянным переменам и умение верифицировать информацию, переобучаться и противостоять стрессу [20], a c другой, позволит педагогам использовать весь арсенал накопленного опыта. Однако всё это не умаляет трудности по претворению в жизнь конвергентного образования, которое базируется на новом научно-технологическом укладе, в основе которого лежат НБИКС-технологии: Н - нано, Б - био, И - информационные, К - когнитивные, С - социальные технологии $[14 ; 21]$.

Развитие современных технологий различного плана, несомненно, определяет и траектории развития образовательной сферы в целом. Наиболее наглядно такие векторы развития отражены в концепт-карте бразильского исследователя Мишеля Заппа, который представил свой масштабный проект Envisioningtech, который, в том числе, охватил и образовательную среду [28]. Представляя основные направления и тенденции развития образовательных технологий в промежутке с 2012 по 2040 г. в виде обширной концепт-карты, автор проекта демонстрирует основные изменения образовательных категорий и их аспекты на примере трёх взаимодействующих сфер обучения: учебной аудитории, мастерской и виртуальной учебной комнаты. Отмечая, что цифровизированные учебные классы уже не являются обособленными инструментами или отдельными навыками и вплетены в образовательный процесс, в частности, в виде интерактивных досок, проекторов, интернета вещей и интернет-подключения, автор проекта указывает на то, что одной из технологий образования будущего является сочетание виртуальной и физической учебной аудитории, так называемой технологии поддержки виртуальных сред, которая позволяет преодолеть разрыв между восприятием учебной обстановки как реальной (оффлайн) и виртуальной (онлайн) [23; 28$].$

Одной из интересных особенностей движения образовательных технологий в новом веке, отмеченных М. Заппа, являются, по нашему мнению, способы распространения и получения учебного материала, так как обмен информацией учебного процесса давно вышел за пределы учебного заведения [23; 28]. Широкое распространение онлайн образовательных сообществ, образовательных приложений и платформ и т.д. предоставляют объёмный доступ к информации, без которого не обходится современная аудитория.

Рассматриваемая концепт-карта не только даёт представление о многочисленных составляющих сложного процесса обучения, но и отражает вектор развития образовательной сферы на следующие десятилетия. Автор проекта показывает, как к 2020 г. должен произойти наглядный сдвиг в сторону цифровой учебной обстановки начиная с 2012 г. И, по предположениям автора, к 2040 г. традиционному учебному классу будет отведено менее 20 \% ныне существующего образовательного пространства [23; 28].

В текущий период 2020-2021 гг., согласно М. Заппа, с использованием интернета вещей, образовательных платформ и персонифицированных образовательных программ, а также алгоритмов, созданных для них искусственным интеллектом, студенты смогут самостоятельно взаимодействовать друг с другом без участия педагога [23; 28]. Происходит пересмотр традиционного взаимодействия «преподаватель-учащийся», т.е. отказ от посредничества в процессе обучения, о чём также говорит сингапурский лингвист У. Ренандья [27]. Поддержку такого отхода от устоявшейся модели можно отметить в работе сторонников и пропонентов концепции совместного обучения в языковом образовании Дж.М. Джейкобс и У. Ренандья, которые выделяют восемь преимуществ того, как самостоятельная коллаборация студентов может положительно повлиять на учебный процесс: студенты более активны и мотивированы, испытывают меньше волнения, более глубоко вникают в учебный материал, становятся более самостоятельными, но в то же время могут получить больше помощи от своих напарников и, в итоге, научаются большему и с большим удовольствием [25: с. 3-9]. В этом случае новые технологии предлагают каждому учащемуся персонификацию самого процесса с применением искусственного интеллекта. 
Интересно также предположение М. Заппа о том, что $65 \%$ нынешних выпускников школ будут заняты в профессиях, которых ещё не существует [28], а профессор Т.Н. Черниговская уверена, что в будущем многие профессии станут невостребованными, так как большую часть работы начнут делать роботы [20].

В указанных работах зарубежных специалистов отражается суть идеи цифровой трансформации образования в целом - эффективно и гибко применять новейшие технологии для перехода к персонализированному и ориентированному на результат образовательному процессу.

Возникает вопрос: каким образом мы можем выстроить систему образования, учитывая все требования, в мире, который стал нечеловекомерен? Учёные настаивают на том, что образование должно стать образованием понимания, а не образованием заучивания. В ученике необходимо воспитывать стремление к постоянным изменениям, подвергать информацию постоянной верификации, практикуя вариативное образование [3].

Цифровизация порождает всё новые вопросы, относящиеся к этике преподавания и философии образования. Миссия преподавателя всегда была миссией наставника. Цифровая среда требует от преподавателя другого менталитета в рамках изменившейся картины мира, иных способов и форм работы с учениками. Преподаватель должен выступать в роли шерпы, проводника по цифровому миру. Он передаёт ученику знания, помогает ориентироваться в информационной среде, помогает формировать умения и навыки. В своё время выдвигались предположения, что преподаватель может быть полностью заменён и процесс обучения может быть полностью интерактивным. Резкий переход от стандартного формата обучения к дистанционному в 2020 г. показал психологическую неготовность студентов и преподавателей к восприятию данного формата образования как полноценного [2].

«Нецифровой» преподаватель чувствует аудиторию, строит занятие с учётом возможностей и интересов своих студентов, поэтому его полная замена цифровыми технологиями категорически невозможна. Вряд ли кто-то сочтёт видеозапись урока способной заменить реальное занятие. Говоря о цифровом образовании, мы говорим о создании необходимых «цифровых помощников» преподавателя, а не о его заменителях.

В последнее время в сфере образования используются термины «Образование 2.0», «Образование 3.0» [2]. Это проекты, которые достаточно активно обсуждаются в настоящее время. «Образование 2.0» связано с высокой степенью интерактивности учащихся и постоянной обратной связью между педагогом и учеником. «Образование 3.0» предполагает использование веб-сервисов для со- здания образовательной среды, и сам учебный процесс утрачивает свои временные ограничения. Данная модель строится на идеях самостоятельного поиска, открытий и выводов ученика. В этом случае педагог становится фасилитатором, внедряющим в процесс обучения лучшие практики самообразования, а обучающийся уже сам выстраивает процесс.

В современной модели обучения предполагается интеграция очных и дистанционных форм обучения. Большинство учёных считают, что цифровые средства призваны служить улучшению качества самого процесса обучения, а не просто тому, чтобы являться техническим дополнением уже существующей системы. Обучение с помощью цифровых технологий представлено многообразием образовательных стратегий [6], что предполагает индивидуализацию учебного процесса, возможность интенсификации процесса обучения, ориентацию на самообразование [9].

В настоящее время наибольший акцент в обучении делается на кейс технологии, ведущие к самостоятельному изучению материала; ТВ-технологии, использующие возможности телевидения; сетевые технологии обучения, использующие локальные и глобальные сети и сети Интернет (форум, чат, обмен сообщениями). К интерактивным элементам дистанционного обучения можно отнести и организацию проверки выполненных заданий через задания преподавателя, рабочую тетрадь, опрос на уроке, вебинар, тесты [17].

В современных образовательных технологиях можно выделить три наиболее перспективных направления: развитие творческих способностей учащихся (игровые технологии, имитационные игры); самостоятельный поиск информации (компьютерные технологии, включающие технологии презентации, обучающие программы, интерактивные доски, построение компьютерных моделей, технологии проектов, информационное использование компьютера); преодоление индивидуальных недостатков и активизацию творческого потенциала учащегося (технологии индивидуально-дифференцированного интерактивного обучения). Кроме того, возможно использование инновационных методов диагностики: электронных тестов для проверки и коррекции знаний, привлечение электронных баз данных.

Согласно результатам мониторинга глобальных трендов цифровизации [12] ключевыми направлениями для сферы образования являются мобильные технологии, искусственный интеллект, технологии интернета вещей, робототехника, облачные технологии, работа с большими объёмами данных, технологии дополненной реальности. При этом исследователями установлены ключевые отраслевые тренды цифровизации образования: «геймифика- 
ция образования» (развитие и внедрение компьютерных игр); расширение использования облачных технологий; развитие решений дополненной реальности; использование социальных сетей в образовании; развитие дистанционного образования, массовых открытых онлайн курсов (МООК); развитие технологий визуализации.

Специалисты полагают, что учебные классы должны имитировать рабочие места, поэтому необходимо создавать в них условия для совместной работы обучающихся путем организации трансформируемого рабочего пространства на основе использования современных цифровых технологий: «умных» досок (Smart Boards), «умных» парт (Smart Desks) и др. Искусственный интеллект позволяет проводить детальный анализ процессов в системе образования. С помощью современных электронных устройств становится возможным мгновенно получать информацию и своевременно принимать решения, а также учитывать способности и интересы обучающегося и создавать для каждого индивидуальную траекторию развития [12].

В образовательный процесс с применением цифровых технологий предлагают перевести профильные курсы, углублённые курсы по профильным предметам, проектную и исследовательскую деятельность учащихся, индивидуальные программы обучения, учитывающие особенности преподаваемого предмета и психологические особенности студентов [17].

Из этого следует, что педагогам необходимо дополнительное обучение для преподавания в современных условиях через развитие персонифицированных моделей повышения квалификации, организацию сетевых проектов и конкурсов, формирование сети стажёрских площадок с целью передачи эффективного педагогического опыта, внедрения вебинаров и т.д. [16].

Функции преподавателя в условиях интернетобучения расширяются и, кроме традиционных функций, преподаватель также организует работу по созданию учащимися телекоммуникационных проектов, проводит интернет-дискуссии и интернет-конференции, проводит онлайн консультации, разрабатывает различные дидактические модели на базе сетевого ресурса.

Важнейшей функцией преподавателя становится разработка, проверка и претворение в жизнь программных средств обучения, включая материалы для самоподготовки. На преподавателя, таким образом, ложится ответственность за разработку курса на новой технологической основе, нахождение оптимального образовательного режима для определённого студента, обеспечение активного всестороннего взаимодействия во время прохождения курса.
Предполагается, что специализация преподавателей в новых условиях работы будет выражена более ярко и чётко через четыре основных направления деятельности, таких как: разработчик курсов или дизайнер; фасилитатор, консультант по методам обучения; тьютор, занимающийся непосредственно преподаванием учебных курсов; специалист по методам контроля, отвечающий за проведение тестов, зачётов и экзаменов [7].

При таком разнообразии профессиональных задач, с одной стороны, и предполагаемой необходимости в силу нынешних условий российской образовательной системы совмещать всё вышеперечисленное в работе одного педагога, с другой, не представляется возможным выполнять такой широкий охват видов деятельности без ущерба для качества преподавания.

Успешность деятельности преподавателя, кроме владения техническими средствами обучения, на наш взгляд, будет проявляться в следующих критериях: удовлетворённости учащегося процессом обучения, проявлении учащимся активности в учебной и общественной деятельности, бесконфликтности в сложившейся системе взаимоотношений с окружающими.

На платформе Google-Класс был разработан курс «Практика применения цифровых ресурсов», ориентированный на студентов, обучающихся на педагогических направлениях, а также на учителей.

Электронный курс имеет модульную структуру. Каждый модуль представляет собой фрагмент, направленный на формирование определенных знаний и умений в области использования цифровых ресурсов. Курс включает в себя изучение таких образовательных платформ, как: Российская электронная школа, образовательная платформа «Открытая школа», Яндекс.Школа, Яндекс.Учебник, Яндекс.Класс, Учи.ру [5].

В январе 2020 г. начался проект «Инициатива ФГОС 4.0», который предложили ученые, эксперты и заинтересованная общественность. В основе проекта лежат стратегии вариативного образования. Под вариативностью в данном случае понимается, по Л. Выготскому, возможность выбора «веера социальных ситуаций развития» (Цит. по: [1]). В будущем предполагается смотреть на образование именно через рамку развивающего обучения и культурно-исторической концепции, которую в своё время сформулировали А. Леонтьев, В. Давыдов и Д. Эльконин [1].

Цифровая трансформация процессов в системе образования включает и такие тенденции, как возникновение спроса на образовательные онлайнплатформы с контентом, создаваемым самими пользователями, мобильные и онлайн-курсы со смешанным учебным планом и проектно-ориентированным обучением и др. 
Магистральной проблемой профессионального развития современного педагога является освоение им обновленного инструментария: форм организации образовательного процесса, таких как: дистанционные курсы; микроуроки (концепция поглощения знания небольшими единицами: чтение одного абзаца, просмотр видеоклипа или прослушивание аудиофайла); «перевернутый класс» (англ. flipped classroom - принцип обучения, по которому основное усвоение нового материала учащимися происходит дома, а время аудиторной работы выделяется на выполнение заданий, упражнений, проведение лабораторных и практических исследований); методов, активизирующих взаимодействие учащихся: игровые ситуации; проектное таргетирование (индивидуальные проекты, направленные на определённую группу учащихся); «образовательное событие» (совместная образовательная деятельность, ведущая к повышению мотивации и самостоятельному познанию - фестиваль, ярмарка, выставка, виртуальная экскурсия); цифровых средств организации эффективного образовательного взаимодействия: группы в социальных сетях; видеоматериалы, созданные самостоятельно и существующие в открытом доступе в сети; мобильные электронные образовательные ресурсы; использование дополненной, виртуальной и смешанной реальностей (новая интерактивная технология, которая позволяет накладывать компьютерную графику или текстовую информацию на объекты реального времени, это совмещение на экране двух изначально независимых пространств: мира реальных объектов вокруг человека и виртуального мира, созданного на компьютере) и др.

В 2017 г. Европейской комиссией разработаны критерии цифровой компетентности педагогов (DigCompEdu), включающие 22 компетенции и объединенные в шесть тематических областей: «Профессионализм», «Цифровые ресурсы», «Обучение», «Оценка», «Расширение прав и возможностей обучающихся», «Развитие цифровой компетенции обучающихся» [12]. В области профессионализма компетенции направлены на использование цифровых технологий для профессионального развития и практики.

Современный учитель должен уметь оценивать точность и полезность веб-ресурсов и вебинструментов, разрабатывать авторские материалы для реализации учебной программы, искать и анализировать цифровые инструменты, мотивировать учащихся на разработку своих собственных цифровых инструментов, которые будут помогать им в учебе, создавать учебные ситуации, которые стимулируют и мотивируют обучающихся к участию в проектной деятельности, развивают творческий потенциал и творческое самовыражение учащихся.
Смещая фокус внимания на непосредственно обучение иностранным языкам, отметим, что в анализе эффективности применения цифровых технологий в образовательном процессе следует учитывать особенности внешней и внутренней мотивации учащихся. В современном образовательном процессе комплексный подход к пониманию и реализации их сути осуществляется через инструменты и принципы цифровых технологий - геймификацию и эдьютейнмент (игровое обучение).

В общем смысле геймификация - это концепция, которая использует конкретные механизмы и методы для повышения вовлеченности и изменения поведения и привычек людей. По мнению отечественных исследователей, многие преподаватели видят потенциал геймификации как дополнение к возможностям традиционного обучения. Есть также сторонники изменения всей образовательной парадигмы с акцентом на социальное интерактивное обучение и самообучение, что отвечает задачам цифровизации. Отмечается, что настоящая ценность геймификации состоит в том, чтобы «игровой принцип способствовал созданию осмысленного учебного опыта» [11]. Эдьютейнмент (edutainment) рассматривается как образовательная технология, сочетающая в себе инструменты обучения в контексте развлечения, игры. Она позволяет привлекать в учебный процесс мультимедийные, интерактивные ресурсы, учитывать индивидуальные особенности, реализовывать синхронный и асинхронный формат работы [18].

Высокая мотивированность учащихся может быть одним из показателей эффективности применения цифровых технологий, позволяющих добиться вовлеченности в учебный процесс, приобретать необходимый опыт и практику, мыслить нестандартно, не боясь делать ошибки, развивать самоконтроль и желание погружаться в язык и культуру изучаемого иностранного языка. Нацеленность на индивидуализацию и самостоятельность овладения придает значимость развитию именно внутренней мотивации студентов. Так, согласно отечественному педагогу Г.В. Роговой, основными аспектами внутренней мотивации, являются:

- коммуникативная - умение и желание осуществлять коммуникацию на иностранном языке во всех видах речевой деятельности;

- лингвопознавательная - «положительное отношение к изучению основных свойств языковых знаков», которое достигается через развитие интеpeca к познавательной поисковой деятельности учащимися;

- инструментальная мотивация как следствие положительного отношения учащихся к определенным видам работы [15: с. 25]. 
Однако создание необходимых условий для формирования и развития внутренней мотивации предполагает и трудности, связанные с организацией и осуществлением учебного процесса. Нельзя не учитывать и личность обучающегося в процессе обучения, который не просто сталкивается с высокой технологизированностью жизни, стремительными изменениями экономических и социальных условий жизни в эпоху глобализации, но уже, как указывалось выше, рождён в этой среде и не представляет нецифрового устройства реальности вокруг него [20].

Учитывая вышеуказанные сложности современного этапа развития образования, необходимо отметить, что включение цифровых технологий в процесс обучения иностранным языкам способствует организации языковой среды, в которой искусственным образом имитируются ситуации живого поликультурного взаимодействия в разных форматах. Рассматривая практический аспект использования академических ресурсов неязыкового вуза, обращаем внимание, вслед за исследователем М.В. Захаровой, на цифровые средства обучения английскому как иностранному языку, которые позволили эффективно осуществлять учебный процесс в условиях аудиторного и дистанционного (онлайн) обучения [8].

Прежде всего отметим, что цифровые средства обучения представляют собой интерактивные системы, снабженные анимированной компьютерной графикой, звуком, видеокадрами, статическими текстами и изображениями. В работе с ними пользователю отводится активная роль. Мультимедийные цифровые технологии разработаны для максимально полного вовлечения учащихся за счет различных программ и технических средств, например, тренажёров, тестовых программ, графических редакторов, мультимедийных презентаций, онлайн редактируемых схем, графиков, таблиц и т.п. Среди доступных мультимедийных средств выделим электронные учебники или электронные приложения (версии) учебников:

1) линейка разноуровневой серии Evolve (A1-C1) издательства Cambridge University Press, 2019. Учебник снабжен основными и дополнительными практиками по работе с аудированием, письмом, грамматикой, говорением. QR-коды позволяют подключать мультимедийные ресурсы в учебную аудиторную и самостоятельную работу, осуществляя целенаправленную индивидуализацию обучения, что поддерживает мотивацию студентов;

2) мультимедийные презентации являются эффективной технологией для включения в учебный процесс, могут проводиться как синхронно, так и асинхронно (в записи). Основная цель применения иллюстрирование лекционного материала; закреп- ление новой темы. Ресурсом, который позволяет их создавать, является платформа свободного доступа SlideShare, где преподаватели имеют возможность пользоваться коллекцией готовых шаблонов и презентаций, созданных и размещённых коллегами;

3) цифровой класс - онлайн-ресурс Документы Google, или Google Docs, бесплатное приложение, включающее текстовый редактор, табличный редактор, сервис для создания презентаций, облачный сервис хранения файлов. Инструмент Google Forms позволяет также быстро создавать формыанкеты для опросов и тестирования в режиме multiple choice и автоматически получать результаты ответов и статистику. Особую распространенность получил онлайн-ресурc Google Class, предлагающий бесплатно инструменты для работы с электронной почтой, электронными документами и облачным хранилищем. Его преимуществами являются: а) удобное добавление обучающихся в систему курсов; б) присоединение студентов к курсам с помощью кода и работа с несколькими курсами одновременно; в) создание объявлений; г) импортирование заданий; д) совместное преподавание с большим количеством коллег; е) создание шаблонов и, следовательно, уменьшение времени, затрачиваемого на создание заданий; ж) интегрирование дополнительных материалов (Google Forms, файлов PDF, файлов PPT и др.) с Google Диска [8]. Существует также мобильное приложение, оптимизирующее работу студентов;

4) другими популярными и полезными сервисами являются: Padlet для организации, хранения материалов и совместной работы со студентами; WeVideo - видеоредактор, в котором возможна совместная работа студентов друг с другом и с преподавателем. В нем создаётся видео с различными визуальными и аудиоэффектами, которое также может быть размещено в сети, переработано другими участниками учебного проекта; Zunal (http://zunal.com/), есть возможность создавать вебквесты, что может явиться вполне эффективной формой как организации деятельности студентов в рамках аудиторных занятий, так и формой проверки усвоенных знаний; электронные тренажеры Letter Generator для тренировки навыков написания личных и деловых писем с пошаговыми рекомендациями; тренажер EssayMap для тренировки написания сочинений по готовой схеме с пошаговыми инструкциями; TOEIC Listening - тренажер навыков аудирования, представляющий коллекцию аудиофайлов и упражнений для тренировки аудирования и отработки произношения; Useful English коллекция упражнений на употребление кодифицированного английского языка в устной и письменной форме; веб-ресурс Quizlet с разнообразыми формами работы; Native English (грамматический 
справочник, тесты, словарь идиом), BBC Learning English (ресурс ВВС с подкастами, грамматическими и лексическими упражнениями, новостями, передачами на профессиональные темы), Learn English, British Council (ресурс по изучению General English, Business English, English for Specific Purposes), BBC Language at Work (курс деловой коммуникации в компании); Surveymonkey, Classmaker ресурсы для создания тестов, опросников, викторин. Может применяться как для выполнения различных заданий при применении технологии taskbased learning и content-language integrated learning, так и для получения обратной связи от студентов или преподавателя;

5) цифровые приложения (сайты, позволяющие создавать различные типы графического и текстового контента для учебных целей) для развития у обучающихся навыка самоорганизации: EasyBib данный ресурс может использоваться при написании исследовательских работ как на иностранных языках, так и на русском. Он позволяет автоматически составлять библиографические списки для научных работ, используя стили цитирования, как MLA, APA and Chicago/Turabian; Bubbl.us - интернет-ресурс для создания так называемых mind maps в режиме онлайн. Такие «карты памяти» помогают организовать нужную информацию для её наиболее быстрого изучения, запоминания и повторения.

Вышеназванные цифровые технологии и инструменты открывают новые возможности для преподавания иностранных языков, отвечая потребностям и вызовам современного мира. В настоящее время задача педагога состоит в том, чтобы максимально приблизить образовательную деятельность к мировосприятию современного подростка. Именно информационно-коммуникативные технологии позволяют воспроизвести информацию одновременно в виде текста, графического изображения, звука, речи и видео, к чему с детства и привыкло данное поколение. При этом необходимо подчеркнуть, что само наличие технических средств у обучающихся и их использование в учебном процессе не может являться самоцелью или достаточным для достижения поставленных учебных задач. С методической точки зрения не достаёт методического обеспечения для самостоятельной познавательной деятельности учащихся, а электронные программы и курсы не всегда удовлетворяют всем международным требованиям.

\section{ЛИТЕРАТУРА}

1. Адамский, А. Мыслить проблематикой, действовать институционально / А. Адамский // Образование должно соответствовать жизни в ситуации неопределенности. Экспертные высказывания о развитии российской школы. URL: https://www.kommersant.ru/doc/4364719 (дата обращения: 03.06.2021).
2. Алексеева, Д.А. Преподаватель в контексте цифровизации образования / Д.А. Алексеева, И.Ю. Алексеева // Ведомости прикладной этики. - 2021. - Вып. 57. - С. 83-92.

3. Асмолов, А.Г. Психология перемен. Лидеры изменений: укрощение хаоса / А.Г. Асмолов. - URL: https:// yandex.ru/video/preview/?text=асмолов\%20фильм\%20психологи я\%20перемен\&path=wizard\&parent-reqid=1620091862762265524219335965376950600271-prestable-app-host-sas-web-yp80\&wiz_type $=$ vital\&filmId $=4098315929411610924$ (дата обращения: 03.05.2021).

4. Брызгалина, Е.В. ИИ в образовании: социальнофилософские аспекты / Е.В. Брызгалина. - URL: https:// ntinews.ru/blog/publications/iskusstvennyy-intellekt-v-obrazovanii-sotsialno-filosofskie-aspekty.html (дата обращения: 08.04.2021)

5. Екабсон, С.Я. Обучение педагогов практике применения цифровых ресурсов / С.Я. Екабсон, Е.М. Любимова // Скиф. Вопросы студенческой науки. - 2021. - № 4 (56). C. $161-165$.

6. Ермолаева, T. Цифровое образование / Т. Ермолаева. URL: https://znanio.ru/media/tsifrovoe-obrazovanie-2527928 (дата обращения: 10.04.2021).

7. Жаборовский, И. Роль учителя в условиях внедрения системы электронного обучения E-learning / И. Жаборовский. - URL: https://infourok.ru/doklad_na_temu_rol_ uchitelya_v_usloviyah_vnedreniya_sistemy_elektronnogo_obuc heniya_e-learning-439447.htm (дата обращения: 10.04.2021).

8. Захарова, М.В. Цифровые инструменты преподавания английского языка. / М.В. Захарова // Мир педагогики и психологии: международный научно-практический журнал. - 2020. - № 06 (47). - URL: https://scipress.ru/pedagogy/ articles/tsifrovye-instrumenty-prepodavaniya-anglijskogoyazyka.html (дата обращения: 19.06.2021).

9. Информационно-образовательная среда. Организация коллективной деятельности. - URL: http://900igr.net/ prezentacija/informatika/proekt-sozdanija-modeli-obrazovatelnoj-sredy-nachalnoj-shkoly-rostok-178844/informatsionnoobrazovatelnaja-sreda-4.html (дата обращения: 08.04.2021).

10. Капустина, Л.В. Анализ современных тенденций в применении цифровых технологий при обучении иностранным языкам (на материале обучающих web-сайтов) / Л.В. Капустина // Концепт. - 2020. - № 3. - С. 48-55.

11. Краснова, Т.И. Геймификация обучения иностранному языку / Т.И. Краснова // Молодой ученый. - 2015. № 11 (91). - С. 1373-1375.

12. Курбатова, К.О. Современная образовательная среда как фактор обеспечения качества образовательного процесса / К.О. Курбатова, А.Ю. Зимоглядова // Международный журнал гуманитарных и естественных наук. - 2020. № 10-1 (49). - С. 88-90.

13. Образовательные технологии при обучении дисциплине «Иностранный язык» (английский). - URL: https:// study-english.info/work_program_political04.php (датаобращения: 06.04.2021).

14. Понятие и определение конвергентного образования. - URL: https://nsportal.ru/shkola/obshchepedagogicheskietekhnologii/library/2018/07/19/ponyatie-i-opredelenie-konvergentnogo (дата обращения: 14.04.2021).

15. Рогова, Г.В. Методика обучения иностранным языкам в средней школе / Г.В. Рогова. - Москва : Просвещение, 2011. - 188 c.

16. Современные модели повышения ИКТ-компетентности педагогов. - URL: http://900igr.net/prezentacija/ informatika/rol-informatsionnykh-tekhnologij-v-modernizatsiisistemy-obrazovanija-nizhegorodskoj-oblasti-165526/sovre- 
mennye-modeli-povyshenija-ikt-kompetentnosti-pedagogov24.html (дата обращения: 10.04.2021).

17. Топ-10 лучших платформ для создания и проведения онлайн-обучения. - URL: https://partition-magic-ru.ru/lucsieprogrammy-dla-distancionnogo-obucenia (дата обращения: 08.04.2021).

18. Фёдоров, О.Д. Edutainment - новая концепция современного обучения? / О.Д. Фёдоров. - URL: https://rosuchebnik.ru/upload/iblock/3c8/3c8a3f8360be372c6313fd67a351a 3f3.pdf (дата обращения: 08.04.2021).

19. Чекун, О.А. Современные технологии в обучении иностранным языкам цифрового поколения студентов / О.А. Чекун, И.И. Лушникова // Теория и методика профессионального образования. - 2015. - № 1. - С. 69-73.

20. Черниговская, Т.В. Человек в цифровом мире / T.B. Черниговская. - URL: https://psy.su/feed/6900/ (дата обращения: 13.04.2021).

21. Что такое конвергентный подход в образовании? URL: https://ino.mgpu.ru/notes/konvergentnoe-obrazovaniekakprimenyat-novyj-podhod-na-obychnyh-urokah/ (дата обращения: 14.04.2021).

22. Bersin, J. The Blended Learning Book: Best Practices, Proven Methodologies, and Lessons Learned / J. Bersin. 1st edition. - San Francisco : Pfeiffer Publishing, 2004. - 352 p.
23. Heick, T. What is the Future of Classroom Technology? / T. Heick. - URL: https://www.teachthought.com/the-futureof-learning/6-characteristics-of-tomorrows-classroom-technology/?fbclid=IwAR3iP0_h82InB_ZWEPWU78HRBhlYuNPPE NfOqFpeXWOv2f70XFZgStlD-xk (accessed: 06.04.2021).

24. Innovations in learning technologies for English language teaching / Ed. Gary Motteram. - London : British Council, 2013. - $197 \mathrm{p}$

25. Jacobs, G.M. Cooperative Learning in Language Education / G.M. Jacobs, W.A. Renandya. - Singapore : Springer, 2019. $-81 \mathrm{c}$.

26. Kintu, M.J. Blended learning effectiveness: the relationship between student characteristics, design features and outcomes / M.J. Kintu, C. Zhu, E. Kagambe. - URL: https:// doi.org/10.1186/s41239-017-0043-4 (accessed: 26.06.2021).

27. Renandya, W.A. Student-Centred Learning / W.A. Renandya // Plenary speech delivered at the webinar "StudentCentred Learning in Blended Learning Environments". - University of Santo Tomas, Manila, 10 April 2021. - URL: https://drive.google.com/file/d/11F_xRSsjrmncQ9vX0xk4nLYL epL1ErRR/view (accessed: 06.04.2021).

28. Zappa, M. Envisioningtech. Personal Website / M. Zappa. - URL: http://mz.wtf/envisioning (accessed: 06.04.2021). 